\title{
Favorable Biological Responses of Neural Cells and Tissue Interacting with Graphene Oxide Microfibers
}

\author{
Ankor González-Mayorga, ${ }^{\dagger}$ Elisa López-Dolado, ${ }^{\dagger}{ }^{\ddagger}$ María C. Gutiérrez, ${ }^{\S}$ Jorge E. Collazos-Castro, ${ }^{\dagger}$ \\ M. Luisa Ferrer, ${ }^{\S}$ Francisco del Monte, ${ }^{\S}$ and María C. Serrano ${ }^{*, \$, \S \odot}$ \\ ${ }^{\dagger}$ Hospital Nacional de Parapléjicos, Servicio de Salud de Castilla-La Mancha (HNP-SESCAM), Finca La Peraleda s/n, 45071 Toledo, \\ Spain \\ ${ }^{\ddagger}$ Research Unit of “Design and Development of Biomaterials for Neural Regeneration”, Hospital Nacional de Parapléjicos \\ (HNP-SESCAM), Joint Research Unit with CSIC, 45071 Toledo, Spain \\ ${ }^{\S}$ Materials Science Factory, Instituto de Ciencia de Materiales de Madrid, Consejo Superior de Investigaciones Científicas \\ (ICMM-CSIC), Calle Sor Juana Inés de la Cruz 3, 28049 Madrid, Spain
}

\section{Supporting Information}

\begin{abstract}
Neural tissue engineering approaches show increasing promise for the treatment of neural diseases including spinal cord injury, for which an efficient therapy is still missing. Encouraged by both positive findings on the interaction of carbon nanomaterials such as graphene with neural components and the necessity of more efficient guidance structures for neural repair, we herein study the potential of reduced graphene oxide ( $\mathrm{rGO}$ ) microfibers as substrates for neural growth in the injured central neural tissue. Compact, bendable, and conductive fibers are obtained. When coated with neural adhesive molecules (poly-L-lysine and N-cadherin), these microfibers behave as supportive substrates of highly interconnected cultures composed of neurons and glial cells for

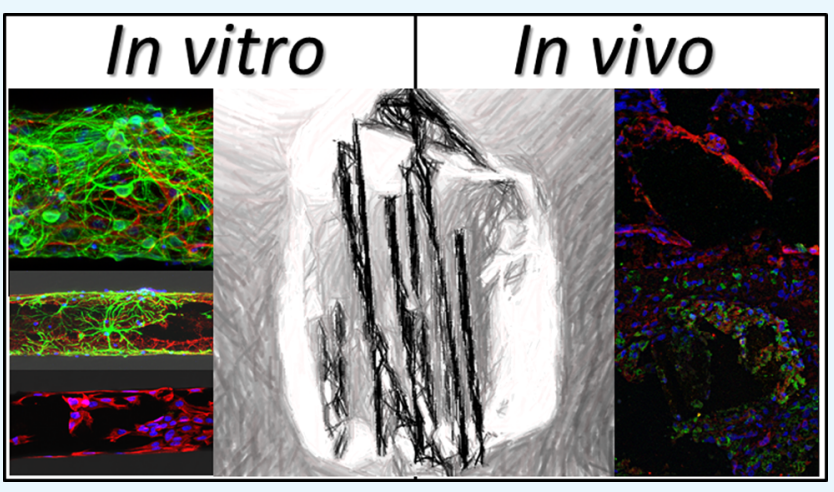
up to 21 days. Synaptic contacts close to rGO are identified. Interestingly, the colonization by meningeal fibroblasts is dramatically hindered by N-cadherin coating. Finally, in vivo studies reveal the feasible implantation of these rGO microfibers as a guidance platform in the injured rat spinal cord, without evident signs of subacute local toxicity. These positive findings boost further investigation at longer implantation times to prove the utility of these substrates as components of advanced therapies for enhancing repair in the damaged central neural tissue including the injured spinal cord.
\end{abstract}

\section{INTRODUCTION}

Reduced graphene oxide ( $\mathrm{rGO}$ ) is characterized by the presence of a variable amount of oxygen-containing functional groups (mainly hydroxyls and epoxies) in the closely packed honeycomb lattice of $\mathrm{sp}^{2}$-bonded carbon atoms. ${ }^{1}$ These groups significantly enhance its hydrophilicity and adsorptive properties, thus boosting its utility in diverse biomedical applications, such as drug/gene delivery, bioimaging, biosensing, stem cell differentiation, and photothermal therapy, to cite a few. ${ }^{2-4}$ More recently, increasing work is noting its attractive potential for the design of neural interfaces for recording/stimulating ${ }^{5}$ and, more rarely, regenerative medicine including neural tissue engineering. ${ }^{6,7}$ In these lines, advances in the development of more efficient neural interfaces would significantly impact society, ${ }^{8}$ as the incidence of lesions affecting the nervous tissue (e.g., spinal cord injury, peripheral nerve loss, and Parkinson's and Alzheimer's diseases) is increasing. Although the toxicity of graphene-derived materials is still an open debate, ${ }^{9}$ most studies support the existence of a safe range of concentrations for their use in biological scenarios. ${ }^{10}$ When evaluated with neural cells in vitro, positive findings from hybrid structures with silica nanoparticles ${ }^{11}$ and nanogrids, ${ }^{12}$ among others, prompt further investigation of these materials. In the nervous tissue in vivo, graphene behaves as a permissive material not only for neuron and astrocyte growth but also for neurogenesis. ${ }^{13}$ Recent studies by our group have also demonstrated the ability of rGO in the shape of porous 3D scaffolds to mediating immunomodulatory and angiogenic responses, along with axonal growth, in the injured rat spinal cord after chronic implantation. $^{14}$

The configuration of graphene-derived materials in the shape of fibers is being the focus of extensive research mainly because of their practical relevance for applications such as conducting wires, energy-related devices, actuators, and field emitters. ${ }^{15}$

Received: September 12, 2017

Accepted: November 1, 2017

Published: November 21, 2017 


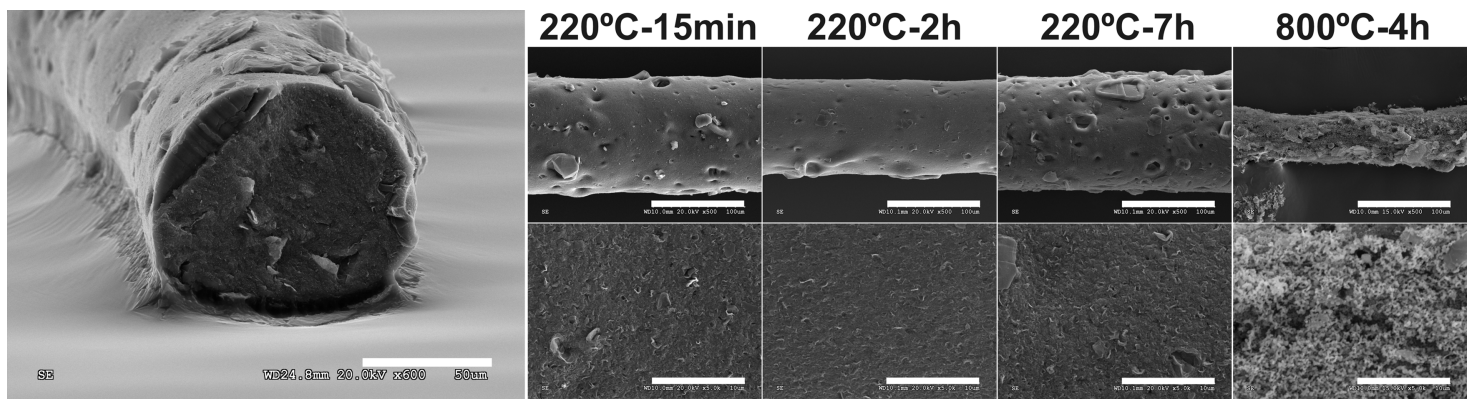

Figure 1. Morphological characterization by SEM of rGO microfibers prepared at different time and temperature conditions. Left image: microfiber prepared at $220{ }^{\circ} \mathrm{C}$ for $2 \mathrm{~h}$. Scale bars: $50 \mu \mathrm{m}$ (left image), $100 \mu \mathrm{m}$ (top), and $10 \mu \mathrm{m}$ (bottom).

Fabrication methodologies under investigation are varied and generally comprise wet-spinning, dry-spinning, dry-jet wetspinning, electrophoretic self-assembly, and film conversion. ${ }^{16}$ In the context of neural repair, a few attempts have been described. Recent work by Guo et al. pioneered the exploration of rGO microfibers fabricated using a capillary hydrothermal methodology for self-powered stimulation of mesenchymal stem cells toward neural phenotypes when functionalized with poly(3,4-ethylenedioxythiopthene) (PEDOT) ${ }^{17}$ and for neural differentiation of neural stem cells. ${ }^{18}$ Similarly, graphene-coated electrospun poly(vinyl chloride) nanofibers demonstrated usefulness as substrates for electrical stimulation of the growth of primary motor neurons. ${ }^{19}$ Other studies regarding electrical stimulation for neural differentiation include the exploration of rolled GO foams. ${ }^{20}$ In a different work, GO promoted the growth and alignment of PC-12 cells and Schwann cells when used as a coating for aligned poly-L-lactide nanofibrous scaffolds. ${ }^{21}$ Additional biomedical uses of GO fibers include their interest as constituents of sensors. ${ }^{22}$

Current approaches for neural repair at the central nervous system include delivery of neurotrophic factors, drug and cell therapies, and implantable biomaterials. ${ }^{23}$ At the injured spinal cord, materials such as agarose, ${ }^{24}$ gelatin, ${ }^{25}$ and chitosan ${ }^{26}$ are under investigation as promising candidates, although effective strategies are still missing. On the basis of biologically positive responses of neural cells and tissues when in contact with carbon nanomaterials, ${ }^{27}$ we herein investigated the potential of rGO in the shape of microfibers as selective substrates for neural tissue engineering with superior guidance performance due to their 3D fibrillary architecture. First, the physicochemical properties of the microfibers were carefully characterized, including morphology, topography, surface chemical composition, conductivity, and flexibility. After biological functionalization with poly-L-lysine and $\mathrm{N}$-cadherin, the in vitro behavior of cortical neural progenitor cells and meningeal fibroblasts in culture on the microfibers was thoroughly investigated by immunofluorescence and electron microscopy studies. Finally, in vivo studies in the injured rat spinal cord were carried out to both prove their feasible implantation and explore the subacute tissue responses induced in vivo.

\section{RESULTS AND DISCUSSION}

GO sheets were obtained by chemical oxidation of commercial graphite powder as previously described. ${ }^{28}$ The resulting GO sheets were then dispersed in distilled water $\left(5 \mathrm{mg} \mathrm{mL}^{-1}\right)$ and used for the fabrication of rGO microfibers by a one-step dimensionally confined hydrothermal strategy. ${ }^{29}$ This thermal process also allowed for the reduction of highly reactive oxygen-containing groups in GO, which are thought to mediate cell toxicity. ${ }^{30}$ In an attempt to achieving significantly distinct redox states of the GO sheets, two dramatically different temperatures $\left(220\right.$ and $800{ }^{\circ} \mathrm{C}$ ) were selected on the basis of previous findings on thermal effects in graphite oxide. ${ }^{31}$ The morphology of the resulting free-standing rGO microfibers was then characterized by scanning electron microscopy (SEM) (Figure 1). As can be observed, modifications in the heating time and temperature used for the hydrothermal process resulted in microfibers with diverse diameters and surface topographies. At $220{ }^{\circ} \mathrm{C}$, all of the microfibers obtained were compact, with diameters of $130.1 \pm 0.02 \mu \mathrm{m}\left(220^{\circ} \mathrm{C}, 15 \mathrm{~min}\right)$, $121.1 \pm 4.99 \mu \mathrm{m}\left(220^{\circ} \mathrm{C}, 2 \mathrm{~h}\right)$, and $128.7 \pm 3.59 \mu \mathrm{m}\left(220^{\circ} \mathrm{C}\right.$, $7 \mathrm{~h}$ ), which displayed no statistically significant differences (ANOVA-post hoc: $p>0.05$ ). However, posterior thermal treatment at $800{ }^{\circ} \mathrm{C}$ for $4 \mathrm{~h}$ significantly reduced the microfiber diameter $\left(54.2 \pm 3.51 \mu \mathrm{m}\right.$, ANOVA-post hoc: $\left.p<0.000^{* * *}\right)$. Microfibers formed at $220{ }^{\circ} \mathrm{C}$ for $7 \mathrm{~h}$ displayed more evident surface holes, which conferred a more irregular topography and, necessarily, a more fragile mechanical performance. The general trend of diameter decrease observed in GO microfibers exposed to higher temperatures and heating times could be related to the progressive reduction of GO sheets and their subsequent more largely confined packing. Specifically, GO sheets go from experiencing strong hydrophilicity and electrostatic repulsion when randomly dispersed in water to become regionally hydrophobic by exposure to the hydrothermal treatment. Hydrophobic and $\pi-\pi$ interactions lead then to $3 \mathrm{D}$ random stacking of flexible graphene sheets. ${ }^{32}$ Slight nonsignificant differences in microfiber diameter outside of this trend might be ascribed to the critical microfiber drying process.

The electrical properties of these microfibers were then explored as the thermal treatment used for the coagulation of the GO sheets in the pipeline was expected to increase their reduction state. Chronoamperometric studies demonstrated a linear relation between intensity and voltage (Figure $2 \mathrm{~A}$ ), with conductivity values of $4.64 \pm 0.90 \mathrm{~S} \mathrm{~cm}^{-1}\left(220{ }^{\circ} \mathrm{C}, 2 \mathrm{~h}\right)$. Interestingly, these values are in agreement with those previously reported for rGO microfibers fabricated by similar methods on glass pipelines. ${ }^{17,18,29,33}$ Although not explored in this work, this finding paves the way for future benefits in the application of these microfibers in electrostimulation protocols both in vitro ${ }^{20,34}$ and in vivo. ${ }^{35}$ As predicted, microfibers obtained by a shorter thermal treatment $\left(220{ }^{\circ} \mathrm{C}, 15 \mathrm{~min}\right)$ displayed a slightly smaller conductivity $\left(2.64 \pm 0.47 \mathrm{~S} \mathrm{~cm}^{-1}\right.$; $t$ test: $\left.p=0.007^{* *}\right)$, whereas those additionally exposed to a more severe thermal treatment $\left(800{ }^{\circ} \mathrm{C}, 4 \mathrm{~h}\right)$ had significantly higher values $\left(85.23 \pm 8.54 \mathrm{~S} \mathrm{~cm}^{-1}\right.$; $t$-test: $\left.p<0.000^{* * *}\right)$ due to a significantly larger reduction degree achieved. ${ }^{31}$ To corroborate that this increase in conductivity was related to 

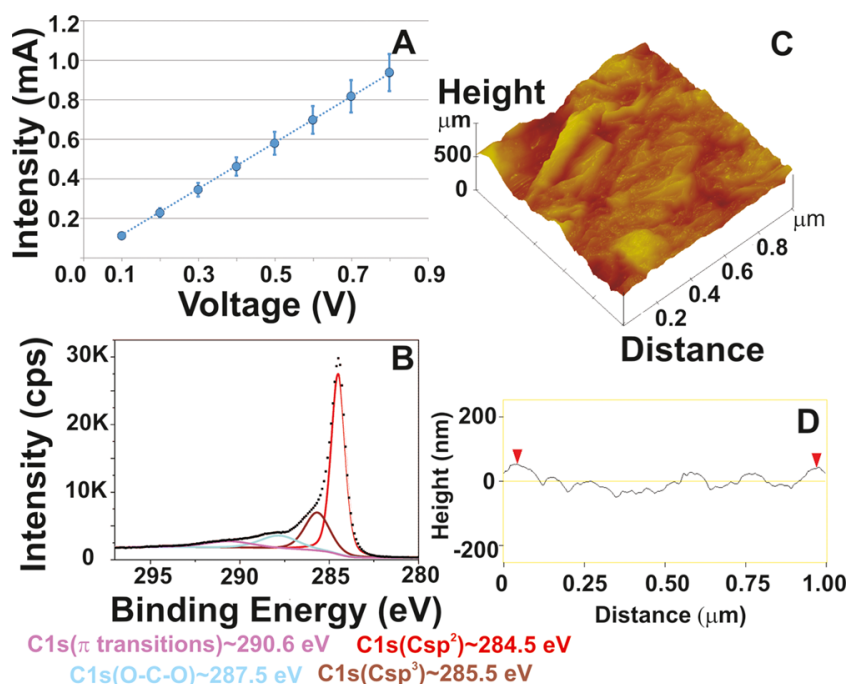

Figure 2. Physicochemical properties of rGO microfibers prepared at $220{ }^{\circ} \mathrm{C}$ for $2 \mathrm{~h}$. (A) Intensity vs voltage plot. (B) C 1s spectrum by XPS. (C) Surface plot and (D) roughness profile by AFM.

GO reduction, X-ray photoelectron spectroscopy (XPS) studies were performed (Figure 2B, Table S1, and Figure S2). A progressive loss of oxygenated groups $(-\mathrm{C}-\mathrm{OH}, \mathrm{O}-\mathrm{C}-\mathrm{O}$, and $\mathrm{O}-\mathrm{C}=\mathrm{O}$ ) was demonstrated as the thermal treatment increased according to the following trend: pristine $\mathrm{GO}>\mathrm{rGO}$ fiber $220{ }^{\circ} \mathrm{C} 15 \mathrm{~min}>\mathrm{rGO}$ fiber $220{ }^{\circ} \mathrm{C} 2 \mathrm{~h}$. Similarly, the percentages of $\mathrm{Csp}^{2}$ and $\mathrm{Csp}^{3}$ increased as well as the $\mathrm{C} / \mathrm{O}$ ratios. Atomic force microscopy (AFM) studies were then used to explore the surface topography of the microfibers (Figure 2C,D). Specifically, root-mean-square ( $\mathrm{rms}$ ) values of $45.23 \pm$ $13.19 \mathrm{~nm}$ were obtained for those microfibers prepared at 220 ${ }^{\circ} \mathrm{C}$ for $2 \mathrm{~h}$. Finally, rGO microfiber flexibility was explored using a semiquantitative bending test (Figure S3). Microfibers fabricated at $220{ }^{\circ} \mathrm{C}$ for $2 \mathrm{~h}$ were able to sustain deformations without rupture for at least $105^{\circ}$ of bending, rarely achieved by any microfibers obtained using the rest of preparation conditions tested in this study.

For the subsequent biological studies in vitro and in vivo, rGO microfibers prepared at $220{ }^{\circ} \mathrm{C}$ for $2 \mathrm{~h}$ were selected due to their more favorable properties including reproducibility (over 150 microfibers prepared), rather than those fabricated at either longer heating times (irregular in their surface morphology) or at a higher temperature (too fragile). Initial studies demonstrated that bare microfibers (devoid of any biological coating) were unable to support the growth of embryonic neural progenitor cells (ENPCs) in vitro (Figure S4), even when previous work by others proved the capacity of this type of microfibers to allow the growth of mesenchymal stem cells and neural stem cells. ${ }^{17,18}$ Therefore, as a necessary step to mediate adhesion of these neural cells, rGO microfibers were coated with either poly-L-lysine (PLL) (adsorbed), conventionally used to favor neural-like cell adhesion, or Ncadherin (either adsorbed, ADS, or covalently bond, COV), an adhesion receptor able to enhance neural cell growth and survival and involved in synapse formation and neuronal physiology. ${ }^{36}$ Modifications of the microfiber surface topography induced by the biological coating were measured by AFM (Figure S5). Specifically, rms values of $7.01 \pm 2.92$ and $10.72 \pm 3.32 \mathrm{~nm}$ were measured for PLL- and N-cadherincoated microfibers, respectively. This result evidenced a significant smoothening effect caused by the biofunctionaliza- tion in both cases ( $t$-tests: $p<0.000 * * *)$, as also observed in $2 \mathrm{D}$ rGO films. ${ }^{28}$ The presence of these biomolecules on the microfiber surface was further confirmed by XPS (Figure S5 and Table S1). Specifically, a significant increase in both oxygen- and nitrogen-containing groups was detected. Neither roughness profiles by AFM nor XPS spectra revealed significant differences between $\mathrm{ADS}$ and $\mathrm{COV}$ microfibers. This finding is not surprising as the most superficial layer was expected to be constituted by $\mathrm{N}$-cadherin molecules in both cases and both techniques provide information from the material surface. Finally, the homogeneity of the biological coatings was corroborated by confocal laser scanning microscopy (CLSM) (Figure S6).

We next explored the ability of these biofunctionalized rGO microfibers to support the formation of neural cultures in vitro both on their surface and at their periphery. To maximize microfiber colonization by cells without introducing additional materials of unknown response with ENPCs, rGO microfibers were glued at their edges to glass coverslips (conventionally used for cell culture), as illustrated in Figure S1. This glass substrate adjacent to the microfibers worked as a necessary control of well-known behavior with ENPCs for comparisons. ${ }^{28}$ ENPCs were seeded on these substrates, and the cultures were maintained for up to 21 days to discard any deleterious effects caused by the substrates at long culture times. SEM studies were then carried out to observe the morphology of the cultures on the microfibers (Figure 3). The formation of highly

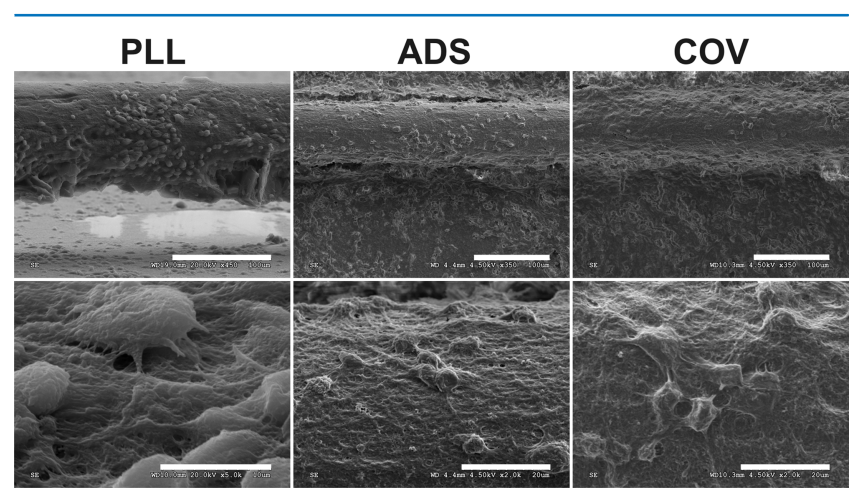

Figure 3. Representative SEM micrographs illustrating ENPC cultures on rGO microfibers coated with poly-L-lysine (PLL), adsorbed $\mathrm{N}$ cadherin (ADS), and covalently bond $\mathrm{N}$-cadherin (COV) for 14 days. Scale bars: $100 \mu \mathrm{m}$ (top), $20 \mu \mathrm{m}$ (ADS and COV, bottom), and 10 $\mu \mathrm{m}$ (PLL, bottom).

interconnected cultures was also corroborated on all of the coated microfibers (PLL, ADS, and COV), with easily identifiable cell somas, neurites, and extracellular matrix components. This supportive behavior of $\mathrm{rGO}$ microfibers for neural cell growth is in agreement with previous results on the use of micro- and nanofibers containing either $\mathrm{rGO}^{17,18}$ or graphene, even when simply used as a dopant ${ }^{37}$ or coating. ${ }^{19,21}$ For instance, GO-coated and aligned poly(L-lactic acid) nanofibrous scaffolds significantly improved the proliferation of rat pheochromocytoma 12 (PC-12) cells and promoted their neural differentiation and neurite growth along the nanofibers. $^{21}$ These substrates also enhanced Schwann cell proliferation and alignment in the presence of nerve growth factor. $^{21}$ In a different approach, hybrid GO nanofibrous scaffolds were able to guide neural stem cell differentiation toward oligodendrocytes, ${ }^{37}$ key players in myelination in the central neural tissue. On the basis of the culture conditions 
used, we hypothesized that a majority of the cells colonizing the microfibers likely migrated from glass coverslip areas in close contact with the microfibers, first reaching the lateral sides of the cylindrical microfibers and then the very top areas, which typically appeared a bit less populated. Although care was taken to preferentially seed the cells on top of the microfibers, their curvature possibly prevented most of the cells to adhere but roll over the fibers and first attach to the fiber lateral sides and glass coverslip areas nearby instead. This hypothesis was proven from cultures in which microfibers remained curved away from the glass substrate and showed poor cell colonization (data not shown).

To further characterize these ENPC cultures, immunofluorescence studies of specific markers were carried out by CLSM. Figure 4A illustrates representative images of ENPCs cultured on coated microfibers (PLL for 21 days; ADS and COV for 14 days). Three-dimensional reconstructions of the z-stacks of these microfibers are provided in the Supporting Information for facilitating the appreciation of the 3D colonization of the substrates by the cells (Movies 1-3). As can be appreciated, both neurons (map-2 $2^{+}$and non-neuronal cells including glial
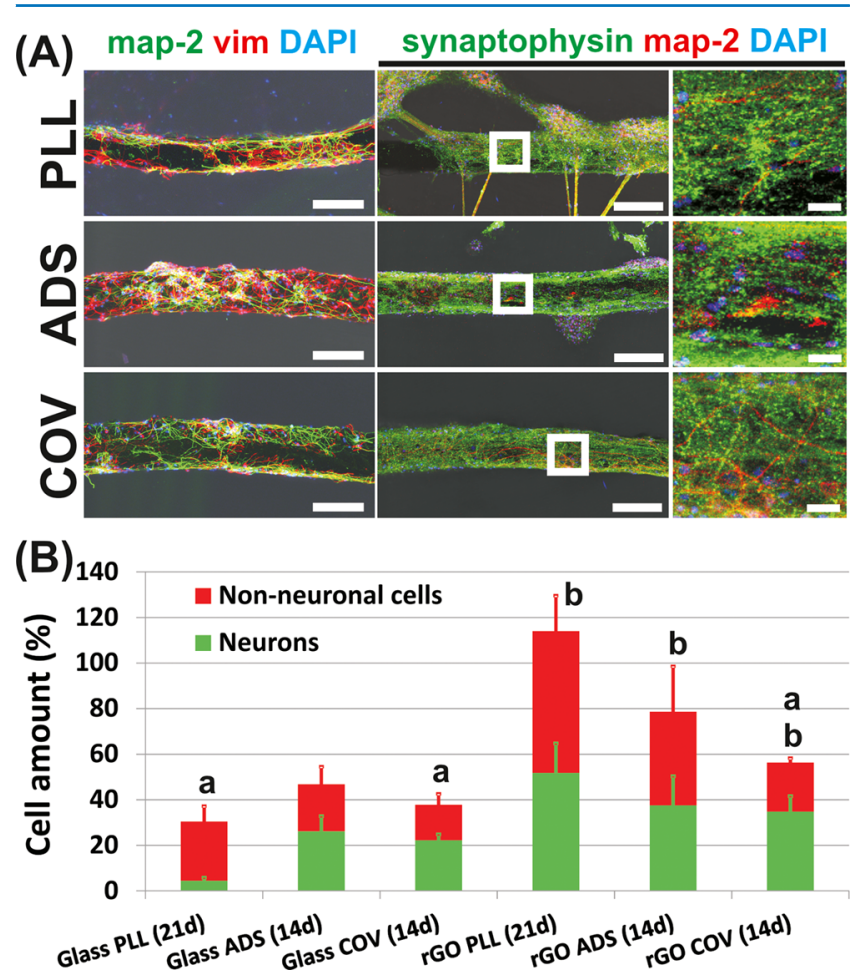

Figure 4. Characterization of ENPCs in culture on biologically coated rGO microfibers by CLSM. (A) Left column, neurons are labeled for map-2 (green) and non-neuronal cells including glial cells for vimentin (red). Cultures correspond to 21 days (PLL) and 14 days (ADS and $\mathrm{COV}$ ). Right columns, neuronal dendrites and somas were labeled for map-2 (red) and synapses for synaptophysin (green). Zoom-in images of the microfibers (white squares) are also included. Cultures correspond to 14 days (PLL, ADS, COV). Scale bars: $150 \mu \mathrm{m}$ (left and middle) and $25 \mu \mathrm{m}$ (right). In all cases, cell nuclei were stained with 4',6-diamidino-2-phenylindole (DAPI) (blue). (B) Percentages of neurons and non-neuronal cells covering the microfibers at the different culture times assessed. Data from peripheral glass coverslip areas at similar culture times are also shown for comparison. Statistically significant differences between cell types for each particular substrate (a) and between rGO microfibers and correspondent glass controls (b) ( $t$-tests, $p \leq 0.05)$. cells $\left(\right.$ vimentin $^{+}$) were present on the fibers, although PLL microfibers needed longer culture times (21 vs 14 days) to reach at least $50 \%$ of the microfiber surface covered by neural cells under these culture conditions. After 21 days, neurons covered $52 \pm 13 \%$ of the PLL-coated microfiber surface, whereas glial cells reached $62 \pm 16 \%$. In $\mathrm{N}$-cadherin-coated microfibers, values from 14-day cultures were $38 \pm 12$ and $35 \pm$ $7 \%$ for neurons and $41 \pm 20$ and $22 \pm 2 \%$ for non-neuronal cells (ADS and COV, respectively) (Figure 4B). Percentages overpassing $100 \%$ were the result of the high confluence achieved in the cultures. Interestingly, in both PLL and ADS microfibers, there was a higher prevalence of non-neuronal cells $\left(\right.$ vimentin $^{+}$) versus neurons, referred as covered area. In all cases, axons extensively grew on the microfiber surface, reaching percentages as high as $88 \%$ at day 14 (Figure S7). The positive charge conferred to the microfiber surface by the amine groups of PLL (confirmed by XPS studies) is likely responsible for this enhanced neural adhesion and branching, as previously reported for functionalized GO films with hippocampal neurons. ${ }^{38}$ In the case of ADS and COV, the supportive effect on neural cell growth found likely relies on the double beneficial role played by $\mathrm{N}$-cadherin, an adhesion molecule that links cytoskeleton components across cell membranes and plays as a ligand-activated receptor capable of initiating intracellular signaling cascades. ${ }^{36}$ Although both types of $\mathrm{N}$-cadherin coatings supported ENPC growth on the microfibers, a higher tendency to the fasciculation of neurites (i.e., neurites gathered together as condensed bundles) and cell clustering (i.e., concentration of cell bodies in groups) was noticed in ADS microfibers, along with an enrichment in non-neuronal cells. These phenomena, typically induced by nonpermissive substrates, might be ascribed to the less stable binding of $\mathrm{N}$ cadherin when adsorbed to the surface rather than when covalently bond. Similar stability issues were observed with several types of biodegradable nanoparticles coated with lysosomal hydrolase arylsulfatase A (ASA). ${ }^{39}$ Three different binding procedures were compared: adsorption, high-affinity binding via the streptavidin-biotin system, and covalent binding. Interestingly, although adsorption allowed higher amounts of ASA binding, rapid and complete desorption occurred in the presence of phosphate buffer or serum as this binding involves weak chemical forces such as electrostatics, hydrogen bonds, hydrophobic interactions, and van der Waals forces. In contrast, stable immobilization with negligible dissociation was achieved by high-affinity and covalent binding, thus becoming more efficient for biomedical applications. Interestingly, ENPCs cultured on PLL-coated glass coverslips evolved to glial-like cell-enriched cultures after 21 days, faster than those on PLL-coated rGO microfibers under the same culture conditions $(4 \pm 1 \%$ of coverage by neurons and $26 \pm$ $7 \%$ by non-neuronal cells; $t$-tests: $p<0.000 * * *$ ) (Figures $4 \mathrm{~B}$ and S8, first column). On the basis of these findings, parameters such as the $3 \mathrm{D}$ configuration and physicochemical properties of the microfiber surface itself, besides their biological coating, could be playing an additional role in the equilibrium between neurons and non-neuronal cells at longer culture times. Additionally, a significant influence of the electrical properties of rGO on these phenomena cannot be discarded as the conductivity of graphene-derived materials has been recently pointed out as a modulator of neural stem cell maturation, with significant influence on membrane electrical parameters, spine density, and synaptic activity. ${ }^{40}$ In these lines, further studies of these microfibers in contact with neural 


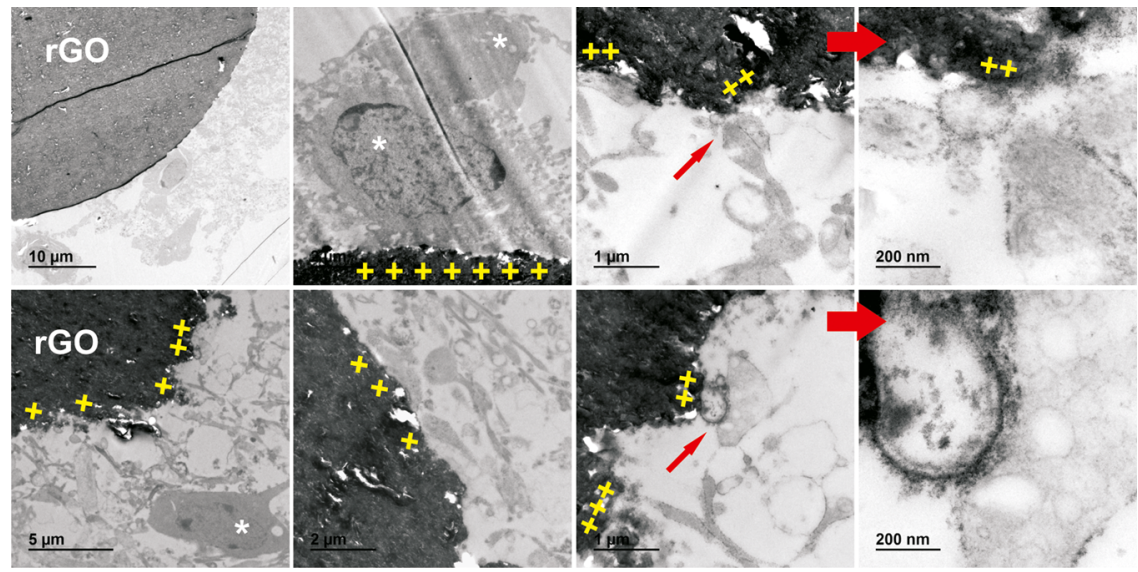

Figure 5. Representative TEM micrographs illustrating ultrastructural details of ENPC cultures on rGO microfibers coated with biological molecules (PLL, top; COV, bottom). Cells in contact with rGO (white asterisks), direct contacts between cellular membranes and rGO (yellow crosses), and synapses in close interaction with rGO (red arrows) are shown. Zoom-in details of structures resembling synaptic bottoms are included in the last column.

components including electrical stimulation procedures both in vitro and in vivo will be the focus of future work. In all immunofluorescence studies, any interference of the rGO microfiber on the fluorescence signals detected was neglected by simultaneous immunofluorescence controls (Figure S9).

Since early times, in neuroscience, synapses have been recognized as functional entities in neural connectivity by means of the establishment of dendritic spines. ${ }^{41}$ Encouraged by recent findings on the ability of graphene to increase spine density, synapse protein expression, and synaptic activity, ${ }^{40}$ we next investigated the presence of synaptic contact components in the ENPC cultures grown on the biologically coated rGO microfibers. Figure 4A (and Movies 4-6 in the Supporting Information) also illustrates representative immunofluorescence images (and 3D reconstructions) of the specific labeling of synaptophysin, a protein related to the regulation of the kinetics of synaptic vesicle endocytosis in central neurons. ${ }^{42}$ As can be appreciated, highly numerous synaptic contacts showing a typical dotlike morphology covered neuronal dendrites and somas (stained in red by simultaneous labeling of map-2) on microfibers, without noticeable differences among biological coatings. Further studies by transmission electron microscopy (TEM) aimed the characterization of the ultrastructure of these neural cultures (Figure 5). Individual neural cells directly adhered to the rGO microfiber surface were frequently identified (white asterisks), as well as highly numerous cell processes. Importantly, direct contacts with rGO were recurrently evidenced not only for cells but also for their processes (yellow crosses). Structures with the appearance of synaptic bottoms were also appreciated in close interaction with the underlying rGO microfiber (red arrows). In line with these results, recent findings have proven the ability of magneticforce-driven GO hybrid patterns containing magnetic nanoparticles to control the accumulation and expression of synaptophysin in human neural cell cultures. ${ }^{43}$ As some recent findings have revealed certain degree of biodegradability for $\mathrm{GO},{ }^{44}$ we also focused on looking for ultrastructural cues of microfiber degradation. Interestingly, neither signs of microfiber structure disassembly nor degradation of the rGO sheets composing it was observed during the 21-day culture. Longer times are likely necessary for the observation of such degradative features, according to a previous work with other carbon-based materials such as carbon nanotubes. ${ }^{45}$
One of the first events taking place at the injured central nervous tissue is the rapid formation of inhibitory fibroglial scars that withdraw reparative initiatives, both internal and external. ${ }^{46}$ To anticipate some insights into the tissue response of these rGO microfibers when implanted in the injured nervous tissue, we investigated in vitro their interaction with primary rat meningeal fibroblasts, cells typically implicated in scar formation and therefore detrimental for neural regeneration when present at the injury site. As evidenced by SEM and CLSM, these cells were able to attach to both bare and PLLcoated microfibers and grow at their periphery without significant differences with control samples (Figure S10). On the contrary, N-cadherin significantly hampered fibroblast cell growth. Importantly, similar effects were found on the peripheral glass areas, thus pointing out $\mathrm{N}$-cadherin as the major factor responsible for this finding. Specifically, substrate coverage reached values of $1.0 \pm 1.6 \%$ on $\mathrm{ADS}$ and $1.4 \pm 1.6 \%$ on $\operatorname{COV}(5.6 \pm 3.9$ and $4.0 \pm 3.4$ for respective glass areas; $t$ tests between microfibers and glass substrates: nonsignificant). Bare and PLL-coated rGO microfibers attained percentages of $34 \pm 18$ and $25 \pm 10 \%$, respectively $(57 \pm 11$ and $24 \pm 15 \%$ for respective glass coverslips; $t$-tests between microfibers and glass substrates: nonsignificant) (comparisons among coatings in rGO microfibers, ANOVA-post hoc: $p=0.001 * * *)$. This finding is not surprising given the specific role of $\mathrm{N}$-cadherin as an adhesion receptor able to enhance neural cell growth and survival and involved in synapse morphogenesis and neuronal physiology. ${ }^{47}$ In line with our findings, Gao and colleagues used neural cell adhesion molecule peptides to functionalize zwitterionic polymer brushes to selectively control directional migration of Schwann cells over fibroblasts. ${ }^{48}$ In a different study, polar polymers bearing cationic charges favored adhesion of glial cells and spiral ganglion neurons over fibroblasts. ${ }^{49}$

Boosted by the attractive physicochemical properties of $\mathrm{rGO}$ microfibers (facile fabrication, reproducibility, guidance architecture, flexibility, and conductivity) and the positive findings in vitro with both ENPCs and meningeal fibroblasts, we next explored the feasibility of implanting these rGO microfibers as a guidance substrate in the injured rat spinal cord. The model of selection for these studies was a lateral hemisection (incomplete lesion at the right side of the spinal cord at C6), which was intendedly selected mainly because it has been proved to provide fair and accurate information about neural 

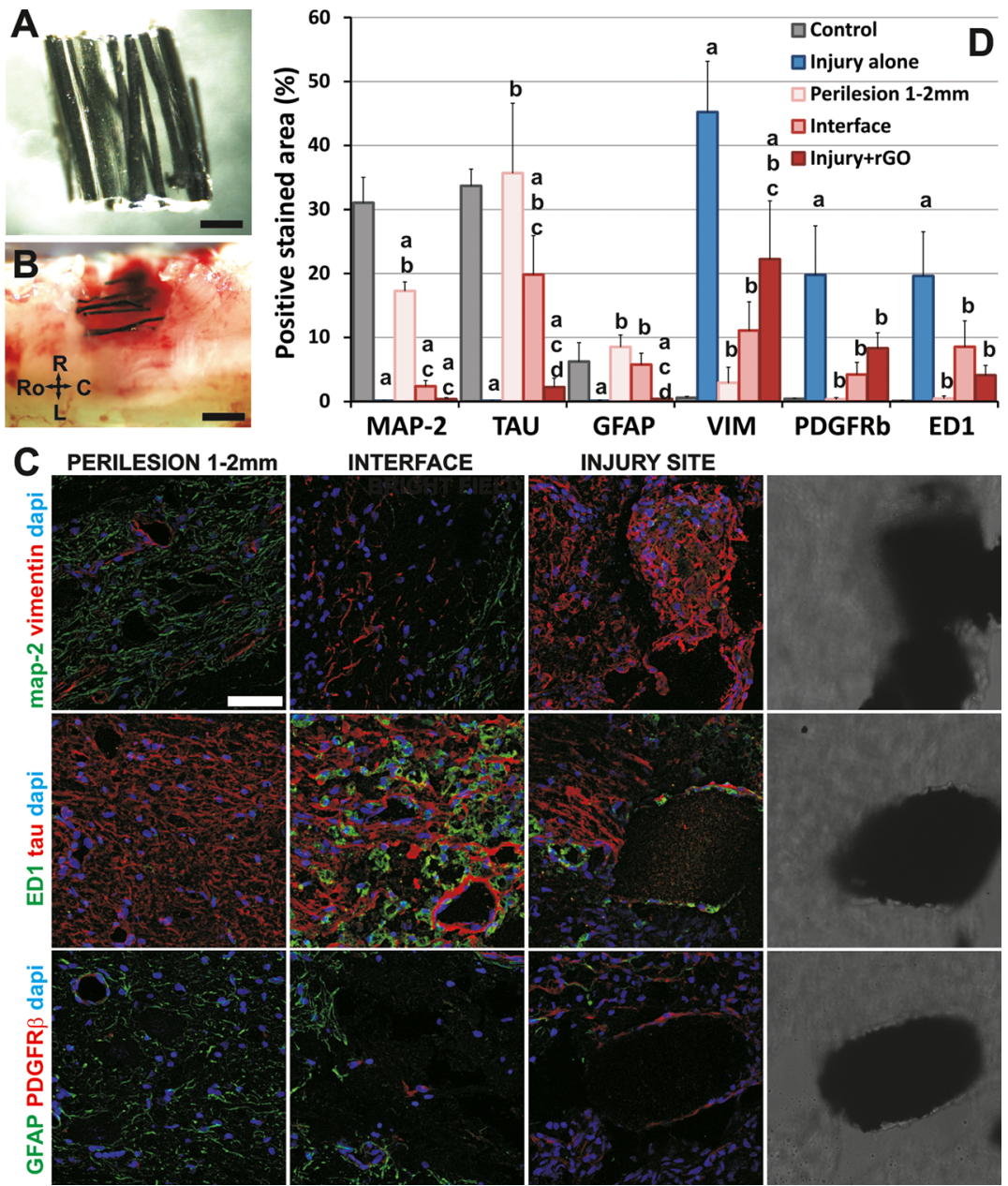

Figure 6. Implantation of rGO microfiber-based scaffolds in the injured rat spinal cord for 10 days. Photographs of an rGO microfiber-based scaffold before (A) and after (B) implantation. The orientation of the tissue is illustrated in the set of arrows (C: caudal, L: left, R: right, Ro: rostral). (C) Representative immunofluorescence images for different markers at three different locations: perilesional areas at $1-2 \mathrm{~mm}$ from the injury, interface, and injury site. Scale bars: $500 \mu \mathrm{m}$ (A), $1 \mathrm{~mm}$ (B), and $50 \mu \mathrm{m}$ (C). (D) Respective quantitative data of positively stained areas for each particular marker. Values for the control and "injury alone" groups are included for comparisons (extracted from previous work by López-Dolado et al. ${ }^{6}$ ). Statistically significant differences were indicated with respect to (a) control, (b) "injury alone", (c) perilesion 1-2 mm, and (d) interface (ANOVApost hoc, $p \leq 0.05)$.

tissue responses while hemisected animals retain a much better general condition after injury, can deal with their handicaps more easily, and are maintained free of the typical chronic complications of this type of lesion. To facilitate implantation, bare rGO microfibers (without either biological coatings or cultured cells) were embedded into a 3D gelatin hydrogel with the dimensions of the injury site (Figure 6A). Typically, a total of 20 microfibers were embedded inside each hydrogel. Prior to implantation, these hybrid scaffolds were cross-linked by exposure to paraformaldehyde vapors to confer mechanical stability to the gelatin polymer. Ex vivo, the resulting scaffolds were stable in PBS at $37{ }^{\circ} \mathrm{C}$ for over 2 months (data not shown). The bendable nature of these microfibers and the soft consistence of the hydrogel were clear advantages that permitted an adequate location in the injury site (Figure 6B). After 10 days of implantation, animals were sacrificed to evaluate the early responses of the neural tissue in close contact with the implant (subacute stage). Figure 6C shows representative immunofluorescence images of specific markers at three locations: perilesional areas at $1-2 \mathrm{~mm}$ from the injury, the interface tissue at the border between structured neural tissue and the injury itself, and microfibers at the very injury site. Respective quantitative data are included in Figure 6D and compared to those of control groups previously published in a similar experimental model. ${ }^{6}$ Panoramic views of tissue sections for all of these markers can be found in the Supporting Information (Figure S11). As can be appreciated, perilesional areas displayed abundant staining for conventional markers of neurons (map-2 and tau) and astrocytes (glial fibrillary acidic protein, GFAP), some positive labeling for vimentin ${ }^{+}$and PDGFR $\beta^{+}$cells (mainly associated with vascular structures and likely representing pericytes), and an almost negligible presence of macrophages (ED1 ${ }^{+}$cells) (differences not statistically significant with respect to control neural tissue except for map-2, ANOVA-post hoc: $p<0.000 * * *)$. At the interface, conventional markers of neurons were still present and coexisted with a slightly higher but not significant abundance of those of reactive cells including astrocytes, connective tissue cells, pericytes, and macrophages (GFAP, PDGFR $\beta$, and ED1, respectively; ANOVA-post hoc: $p>0.05$ with respect to control and perilesional area in all cases). In close contact with the rGO microfibers in the injury site, a majority of cells stained positively for vimentin and PDGFR $\beta$ (ANOVA-post hoc: $p<$ $0.000 * * *$ and $p=0.125$ with respect to control, respectively). 
Macrophages, although contacting the microfiber surface, were less abundant than at the interface but not significantly (ANOVA-post hoc: $p=0.723)$. Some neuronal axons $\left(\mathrm{tau}^{+}\right)$ were able to reach the proximities of the microfibers, in some cases even spreading on the rGO surface. Map- $2^{+}$and $\mathrm{GFAP}^{+}$ cells were rarely found in the immediate periphery of the microfibers (ANOVA-post hoc: $p<0.000^{* * *}$ with respect to control and perilesional areas for both markers). These results are in agreement with previous findings on the subacute implantation of 3D rGO scaffolds, ${ }^{6}$ in which rGO sheets appeared also mainly colonized by cells positive for vimentin, PDGFR $\beta$, and ED1. Interestingly, the implantation of $\mathrm{rGO}$ in the configuration of $3 \mathrm{D}$ microfibers embedded in a gelatin hydrogel seemed to promote a more protective tissue response than the injury alone, as demonstrated by lower percentages of cells positive for vimentin, $\operatorname{PDGFR} \beta$, and ED1 and a higher presence of those positive for tau (ANOVA-post hoc: $p<$ $0.000^{* * *}, p=0.008^{* *}$, and $p<0.000^{* * *}$, respectively). It is worth mentioning that graphene nanosheets have demonstrated also biocompatible and permissive behaviors for neurogenesis when implanted in the mouse olfactory bulb. ${ }^{13}$ In line with these findings, Collazos-Castro et al. recently demonstrated the utility of carbon microfibers $(7 \mu \mathrm{m}$ in diameter) coated with PEDOT and biofunctionalized (by using a multimolecular complex of PLL, heparin, basic fibroblast growth factor, and fibronectin) for promoting tissue healing and enhancing angiogenesis and axonal regeneration, without increasing inflammation, in the injured rat spinal cord. ${ }^{50}$ Further studies at longer implantation times (chronic state) will be necessary to demonstrate the ability of rGO microfibers to enhancing neural repair in the injured spinal cord and to identifying the origin of the cells chronically invading the microfibers. Specifically, current studies in our laboratory are focused on the implementation of the implantation design by modifying the composition and degradation rate of the supportive hydrogel and the functionalization of the microfibers to better favor guidance effects.

To summarize, we have explored the usefulness of bendable microfibers exclusively composed of $\mathrm{rGO}$ as supportive guidance substrates for neural growth both in vitro (by neural progenitor cell culture) and in vivo (by implantation in the injured rat spinal cord). Highly interconnected cultures of central neural cells were formed on the microfiber surface when coated with adhesive biological molecules, such as poly-L-lysine and $\mathrm{N}$-cadherin, but not in their absence. Additionally, by coating with $\mathrm{N}$-cadherin, the colonization of the microfibers by meningeal fibroblasts was dramatically hindered. Finally, in vivo studies revealed the feasible implantation of these rGO microfibers in the injured rat spinal cord and their capacity to be colonized by cells without evidencing signs of subacute local toxicity. These findings encourage further investigation of these graphene-based microfibers at longer implantation times as part of novel neuroregenerative biomaterials for the treatment of lesions at the central nervous tissue including spinal cord injury.

\section{METHODS}

All materials and biological samples in this study were manipulated according to standard regulations, so no safety concerns arise.

3.1. Material. Chemical reagents and antibodies were purchased from Sigma-Aldrich and used as received, unless otherwise indicated. Neurobasal media and B-27 supplement were purchased from Life Technologies. All additional cell culture media supplements and reagents were obtained from Lonza.

3.2. GO Synthesis and rGO Microfiber Preparation and Characterization. GO sheets were obtained by chemical oxidation of commercial graphite powder as previously described. ${ }^{28}$ These sheets were then dispersed in distilled water to a final concentration of $5 \mathrm{mg} \mathrm{mL}^{-1}$. $\mathrm{rGO}$ microfibers were prepared as described elsewhere ${ }^{29}$ and allowed to dry in air overnight. Briefly, the GO suspension (0.5 wt \%) was collected into standard Hirschmann capillary tubes (of 1.35 $\mathrm{mm}$ inner diameter and $120 \mathrm{~mm}$ length), which were thereafter sealed up at their ends. Different heating temperatures and time conditions were investigated for the hydrothermal microfiber preparation. Specifically, thermal treatments at $220{ }^{\circ} \mathrm{C}$ for 15 min, $2 \mathrm{~h}$, and $7 \mathrm{~h}$ were compared. Some microfibers prepared at $220{ }^{\circ} \mathrm{C}$ for $2 \mathrm{~h}$ were additionally exposed to $800{ }^{\circ} \mathrm{C}$ for $4 \mathrm{~h}$ under controlled $\mathrm{N}_{2}$ atmosphere conditions. Those microfibers obtained at $220^{\circ} \mathrm{C}$ for $2 \mathrm{~h}$ were selected for further biological studies based on their more favorable physicochemical properties, including reproducibility, flexibility, and homogeneity. The conductivity of the microfibers was measured using a four-point probe methodology with a 34401A Agilent 61/2 digit Multimeter ( $n \geq 5$ per treatment group). Chronoamperometric measurements were performed on dry microfibers glued to a four-point holder with colloidal graphite using an Autolab Potentiostat/Galvanostat. The electrical current passing through the microfibers was then monitored for fixed voltages from 0.1 to $0.8 \mathrm{~V}$ (steps: $0.1 \mathrm{~V}, 100 \mathrm{~ms}$ ), and measurements were taken every $10 \mathrm{~ms}$. In both cases, the current was introduced and collected through the outer probes, whereas the voltage was measured and fixed between the two inner probes (measurement distance: $0.23 \mathrm{~cm}$ ). XPS studies were performed using a K-Alpha (Thermo Scientific) electron spectrometer equipped with an $\mathrm{Al} \mathrm{K} \alpha(\mathrm{h} v=1486.68 \mathrm{eV})$ Watts X-ray source (12 KV and $6 \mathrm{~mA})(n=40$ scans for complete spectra, $n=75$ for $\mathrm{C} 1 \mathrm{~s}$ and $\mathrm{O} 1 \mathrm{~s}$ and $n=300$ for $\mathrm{N} 1 \mathrm{~s}$ ). The flood gun option was active during the analyses for charge compensation, and the pressure in the analysis chamber was maintained at $2.4 \times 10^{-7}$ mbar. The pass energy of the analyzer was set at $200 \mathrm{eV}$ for complete spectra and $40 \mathrm{eV}$ for zone spectra. The binding energies were referenced to the binding energy of the $\mathrm{C} 1 \mathrm{~s}$ core-level spectrum at $285 \mathrm{eV}$. Data processing was performed with the XPS peak-fit program in Advantage 4.87 software. Spectra were decomposed with the least-squares fitting routine provided by the software with the Gaussian/Lorentzian (90/ 10) product function and after subtracting a Shirley background. Atomic fractions were calculated using peak areas normalized on the basis of sensitivity factors provided by the manufacturer. Surface roughness of the microfibers was studied by AFM (Bruker multimode Nanoscope III A) ( $n \geq 15$ measurements per group). A semiquantitative bending test was carried out by fixing rGO microfibers to a stereotaxic device through their edges $(n=3)$. To drive deformation, a round-tip rod was pressed against the center of the microfiber in a controlled manner.

3.3. rGO Microfiber Functionalization. rGO microfibers were glued at their edges to conventional glass coverslips (12 $\mathrm{mm}$ in diameter) using a medical-grade silicone elastomer (Nusil) and thereafter sterilized by exposure to UV radiation for $30 \mathrm{~min}$. Typically, a total of three microfibers were glued to each coverslip with a separation distance between microfibers of $\sim 2 \mathrm{~mm}$ (Figure S1). Then, substrates (glass coverslips + glued rGO microfibers) were functionalized with either poly-L- 
lysine (PLL; adsorption, $45 \mu \mathrm{g} \mathrm{mL}^{-1}$ ) or $\mathrm{N}$-cadherin (by either adsorption or covalent bonding, $\mathrm{ADS}$ and $\mathrm{COV}$, respectively). $\mathrm{COV}$ functionalization was carried out using a protocol previously described for other type of substrates. ${ }^{51}$ Briefly, substrates were reacted with $\mathrm{N}$-(3-dimethylaminopropyl)- $\mathrm{N}^{\prime}$ ethylcarbodiimide (EDC, $45 \mathrm{mg} \mathrm{mL}^{-1}$ ) and $N$-hydroxysuccinimide (NHS, $45 \mathrm{mg} \mathrm{mL}^{-1}$ ) in distilled water for $1 \mathrm{~h}$ at $24^{\circ} \mathrm{C}$. After three rinses, substrates were incubated in triethanolamine buffer solution for $1 \mathrm{~h}(50 \mathrm{mM}, \mathrm{pH} 8.0)$ containing an IgG antibody against the $\mathrm{Fc}$ fragment of the human $\mathrm{IgG}(100 \mathrm{mg}$ $\left.\mathrm{mL}^{-1}\right)$. This antibody was dialyzed through cellulose ester membranes prior to use. Next, substrates were incubated with recombinant human $\mathrm{N}$-cadherin ( $\mathrm{R} \& \mathrm{D}$ Systems) at $10 \mathrm{mg}$ $\mathrm{mL}^{-1}$ in phosphate-buffered saline (PBS, $\mathrm{pH}$ 7.4) for $1 \mathrm{~h}$. After conjugation, substrates were carefully rinsed. Alternatively, Ncadherin was directly adsorbed to $\mathrm{rGO}$ microfibers without EDC/NHS chemistry by means of the preadsorbed IgG antibody (ADS). The homogeneity of the microfiber coating was confirmed by immunofluorescence (using either PLL-FITC or a primary antibody $\alpha$-N-cadherin followed by a secondary antibody Alexa 633). Control glass substrates were functionalized following the same protocol as that used for rGO microfibers.

3.4. Cell Isolation and Culture. ENPCs were obtained from cerebral cortices of E18 Wistar rat embryos as previously described. ${ }^{52}$ All of the experimental protocols for cell collection adhered to the regulations of the European Commission (directives 2010/63/EU and 86/609/EEC) and the Spanish government (RD53/2013 and ECC/566/2015) for the protection of animals used for scientific purposes. Adult female Wistar rats were provided by a commercial supplier (Harlan Ibérica, Spain) and were sacrificed when gestation reached 18 days. A total of five independent cell cultures from five different animals with a minimum of three replicates per condition in each culture were carried out ( $\geq 45$ microfibers per condition). The viability of the so-isolated cells was $90 \pm 4 \%$ in all cases. To guarantee microfiber colonization, a total of $2.5 \times 10^{4}$ cells contained in a small fraction of media (typically $10 \mu \mathrm{L}$ ) were seeded on the top part of each one and allowed to attach for 10 min. Immediately after, samples were completely covered with $500 \mu \mathrm{L}$ of complete Neurobasal media containing B-27 supplement $(2 \%)$, streptomycin (100 UI $\left.\mathrm{mL}^{-1}\right)$, penicillin $\left(100 \mathrm{UI} \mathrm{mL}^{-1}\right)$, and L-glutamine $(1 \mathrm{mM})$. After $2 \mathrm{~h}$ of adhesion in a sterile incubator at $37{ }^{\circ} \mathrm{C}$ in a $\mathrm{CO}_{2}$ atmosphere (5\%), culture media were replaced and cultures maintained were for up to 21 days. Culture media were half-replaced every 4 days and fully replaced every 7 days. The cell culture was monitored in the periphery of the microfibers using an Axiovert CFL-40 optical microscope with a coupled Axiocam ICC-1 digital camera (Zeiss).

Meningeal fibroblasts were isolated from the cerebral meninges of the rat E18 embryos used for the isolation of ENPCs $(n=3)$. Cells were expanded in vitro to achieve confluent cultures (typically ca. 14 days) in Dulbecco's modified Eagle's medium (DMEM) supplemented with $10 \%$ fetal bovine serum, streptomycin $\left(100 \mathrm{UI} \mathrm{mL} \mathrm{m}^{-1}\right)$, penicillin $\left(100 \mathrm{UI} \mathrm{mL} \mathrm{mL}^{-1}\right)$, and L-glutamine $(1 \mathrm{mM})$. Culture conditions on rGO microfibers were similar to those described for ENPCs, with a cell density of $10^{4}$ cells per microfiber. The high cell seeding density used with both cell types intended to aid microfiber colonization in a shorter period of time, overcoming their cylindrical shape.
3.5. Surgical Procedure and Tissue Processing. Adult male Wistar rats were used at the age of ca. 21 weeks $(n=3$, ca. $400 \mathrm{~g}$ in weight). The lesion model of choice was a right lateral hemisection of approximately $8 \mathrm{~mm}^{3}$ (incomplete lesion) at C6, rostral to the bulk of triceps brachii motoneurons. All experimental procedures in animals were approved by the Animal Research and well-being committee of the Hospital Nacional de Parapléjicos and carried out in accordance with the national and European regulations as indicated above. Specific details on the surgical procedure carried out can be found elsewhere. ${ }^{6,14}$ To facilitate their stable implantation in the injured spinal cord, rGO microfibers were assembled into a $3 \mathrm{D}$ gelatin hydrogel scaffold ( $7.5 \mathrm{wt} \%$ in distilled water) with the dimensions of the lesion site $\left(\sim 8 \mathrm{~mm}^{3}\right.$; $\sim 20$ microfibers per hydrogel). Prior to implantation at the injured rat spinal cord, these hybrid scaffolds were cross-linked by exposure to paraformaldehyde vapors at $4{ }^{\circ} \mathrm{C}$ for 7 days. After implantation, an exhaustive postoperatory animal care protocol was applied with major attention placed into signs of pain, distress, dehydration, intestinal obstruction, and respiratory failure. After 10 days post-injury, rats were sacrificed using a standard perfusion-fixation protocol, and the spinal cords were extracted. Perfused spinal cords were placed in $4 \%$ paraformaldehyde at 4 ${ }^{\circ} \mathrm{C}$ overnight and then 3 days in sucrose (30\% in PBS) at $4{ }^{\circ} \mathrm{C}$ for cryoprotection. $\mathrm{C} 5-\mathrm{C} 7$ spinal cord fragments were mounted on plastic containers, quick-frozen in Optimal Cutting Temperature compound (Tissue Tek, Hatfield, PA), and cut in sagittal sections of $10 \mu \mathrm{m}$ from right to left sides using a Microm HM550 cryostat with an angle of $10^{\circ}$.

3.6. Scanning Electron Microscopy (SEM) Studies. rGO microfibers were rinsed in PBS twice and fixed with glutaraldehyde $(2.5 \%$ in PBS) for $45 \mathrm{~min}$, which is a conventional fixation method for examination by SEM $(n=3$ for each type of bare microfibers, and $n \geq 3$ for each type of cell-cultured ones). After washing in distilled water, dehydration was performed using a series of ethanol solutions for 15 min (two washes) and a final dehydration in absolute ethanol for $30 \mathrm{~min}$. Samples were then dried at room temperature for at least $24 \mathrm{~h}$. After mounting in stubs and gold coating under vacuum, the morphology of the samples was characterized using a Hitachi S-4700 SEM microscope.

3.7. Confocal Laser Scanning Microscopy (CLSM) Studies. ENPC cultures on the rGO microfibers were fixed with paraformaldehyde (4\% in PBS) at room temperature for $12 \mathrm{~min}$ and then incubated with the following primary antibodies: (1) map-2 for somas and dendrites in neurons, (2) tau for axons in neurons, (3) vimentin for non-neuron cells, including glial cells and connective tissue cells as fibroblasts, (4) GFAP for astrocytes, and (5) synaptophysin for synapses. The secondary antibodies used were Alexa Fluor 488 goat $\alpha$-mouse $\operatorname{IgG}(\mathrm{H}+\mathrm{L})$ and Alexa Fluor 594 goat $\alpha$-rabbit $\operatorname{IgG}(\mathrm{H}+\mathrm{L})$ (Life technologies). Both primary and secondary antibodies were dissolved in PBS containing saponin $(0.25 \%)$ and fetal goat serum $(2 \%)$ to guarantee cell permeability and to block any nonspecific bindings, respectively. Each antibody was incubated for $1 \mathrm{~h}$ at room temperature in darkness. Cell nuclei were labeled with 4',6-diamidino-2-phenylindole (DAPI, $3 \mu \mathrm{M}$, $5 \mathrm{~min})$.

Spinal cord tissue samples were examined for the presence of the following markers: (1) map-2 for somas and dendrites in neurons, (2) tau for axons in neurons, (3) vimentin for nonneuron cells including glial and connective tissue cells, (4) GFAP for astrocytes, (5) ED1 for macrophages, and (6) 
platelet-derived growth factor receptor $\beta$ (PDGFR $\beta$ for pericytes, precursors of oligodendrocytes, and connective tissue cells such as fibroblasts and smooth muscle cells). Secondary antibodies were similar to those described above. Cell nuclei were labeled with Hoechst $\left(1 \mathrm{mg} \mathrm{mL}^{-1}\right)$.

After immunostaining, samples were visualized using a Leica TCS SP5 microscope. The fluorescence of the different fluorochromes was excited and measured as follows: Alexa Fluor 488 excitation at $488 \mathrm{~nm}$ with an argon laser and detection in the range $507-576 \mathrm{~nm}$, Alexa Fluor 594 excitation at $594 \mathrm{~nm}$ with a helium-neon laser and detection in the range 625-689 nm, and DAPI/Hoechst excitation at $405 \mathrm{~nm}$ with a diode UV laser and detection in the range 423-476 nm. Capture conditions in each case were established using appropriate positive and negative controls and maintained during the acquisition of all of the images. For each marker, an average of 3 nonoverlapped images was captured per microfiber and coverslip (in vitro studies, $0.3 \mathrm{~mm}^{2}$ per field, $n \geq 15$ images in total) and five independent fields per animal and region (in vivo studies, $0.2 \mathrm{~mm}^{2}$ per field, $n \geq 10$ images in total). The procedure used for the quantification of the immunofluorescence images was based on an automatized protocol created using Fiji software in which the observer must only define a threshold of positive staining for each marker established from the negative controls. To minimize bias effects, quantifications were carried out blind by two independent observers. The area positively stained for each particular marker was expressed as a percentage of the total image area. Additional bright field images were taken to properly define the location of the microfibers in all cases. Panoramic views of cultures and tissue sections were obtained by building mosaics from adjacent micrographs of the entire sample surfaces.

3.8. Transmission Electron Microscopy (TEM) Studies. Following a conventional procedure, in vitro culture samples were first fixed with a mixture of paraformaldehyde (4\%) and glutaraldehyde (1\%) in phosphate buffer for $1 \mathrm{~h}$ and then postfixed in osmic tetroxide ( $1 \%$ in distilled water) for an additional hour. Dehydration was then carried out by immersion in successive solutions of ethanol at increasing concentrations $(30,50,70,95$, and $100 \%)$, with a final step in pure acetone. Samples were included in the resin Durcupán by consecutive immersion steps at increasing concentrations (1:3, $1: 1$, and $3: 1$ in acetone). The final samples in pure resin were then polymerized at $60{ }^{\circ} \mathrm{C}$ for $48 \mathrm{~h}$. Ultrathin sections (ca. 60 $\mathrm{nm}$ ) were obtained and subsequently stained with uracil acetate and lead citrate. The visualization was carried out using a Jeol JEM 1010 microscope (Tokyo, Japan) at $80 \mathrm{kV}$ with a coupled camera (Gatan SC200, Pleasanton, CA) for image acquisition ( $n=5$ microfibers, $n \geq 30$ images).

3.9. Statistics. Quantified parameters were expressed as the mean \pm standard deviation (in all cases, $n \geq 3$ ). When necessary, statistical analyses were performed using Statistical Package for Social Sciences software (SPSS, version 17.0). Comparisons between groups were carried out using Student's $t$-test. When more than two experimental groups were compared, analysis of variance (ANOVA) followed by either Scheffé or Games-Howell post hoc tests (homogeneous and heterogeneous variances, respectively) was used. The statistical significance levels were defined as follows: $p<0.05^{*}, p<$ $0.01^{* *}$, and $p<0.005^{* * *}$.

\section{ASSOCIATED CONTENT}

\section{Supporting Information}

The Supporting Information is available free of charge on the ACS Publications website at DOI: 10.1021/acsomega.7b01354.

Three-dimensional reconstructions of the z-stacks of microfibers (Movies 1-6) (AVI)(AVI)(AVI)(AVI)(AVI)(AVI)

Table containing XPS data, photograph of the microfibers setting on coverslips, controlled deformation test, immunofluorescence images of ENPC cultures on uncoated microfibers, AFM and XPS data from coated microfibers, immunofluorescence images of biological coatings in microfibers, immunofluorescence images of tau and GFAP in ENPC-cultured microfibers, CLSM fluorescence images of ENPC cultures on glass coverslips, secondary antibodies control staining of microfibers, SEM and CLSM images of meningeal fibroblasts on microfibers and glass coverslips, panoramic fluorescence images of $\mathrm{C} 5-\mathrm{C} 7$ spinal cord sections for the different markers used (PDF)

\section{AUTHOR INFORMATION}

\section{Corresponding Author}

*E-mail: mc.terradas@csic.es. Phone: +34 913348995. Fax: +34 913720623.

ORCID $\odot$

María C. Serrano: 0000-0002-5010-644X

\section{Author Contributions}

A.G.-M., M.C.G., and M.C.S. were responsible for microfiber preparation. M.C.G., J.E.C.-C., M.L.F., F.d.M., and M.C.S. performed the physicochemical characterization of the samples. A.G.-M. and M.C.S. carried out microfiber functionalization and neural cell cultures. E.L.-D. and M.C.S. performed in vivo studies. A.G.-M. processed tissue samples and performed immunofluorescence techniques. J.E.C.-C. advised on microfiber functionalization and neural cell cultures. M.C.S. was responsible for fluorescence images' acquisition and processing. All authors participated in manuscript preparation, writing and revision.

\section{Funding}

This work was supported by the Instituto de Salud Carlos IIIMINECO-FEDER (CP13/00060), the Ministerio de Economía y Competitividad, and the Fondo Europeo de Desarrollo Regional (MAT2016-78857-R and MAT2015-68639-R, MINECO/ FEDER, UE). It was also partially funded by the European Union's Horizon 2020 research and innovation programme under grant agreement No. 737116.

Notes

The authors declare no competing financial interest.

\section{ACKNOWLEDGMENTS}

Authors thank Prof. M. Teresa Portolés from Universidad Complutense de Madrid for fruitful discussions and Dr. André Espinha from ICMAB-CSIC for help with mechanical testing and image processing. Drs. Jose Ángel Rodríguez and Javier Mazario from the Service of Microscopy and Image Analysis at the Hospital Nacional de Parapléjicos are acknowledged for assistance with CLSM studies and support with Fiji analyses. The authors are thankful to Drs. Enrique Rodriguez, Francisco Urbano, and Covadonga Agudo from the Servicio Interdepartamental de Investigación at the Universidad Autonoma de Madrid 
for respective assistance with SEM and TEM studies, and Dr. Daniel Gamarra from the SAIUEx for XPS studies.

\section{REFERENCES}

(1) Dreyer, D. R.; Park, S.; Bielawski, C. W.; Ruoff, R. S. The chemistry of graphene oxide. Chem. Soc. Rev. 2010, 39, 228-240.

(2) Feng, L.; Wu, L.; Qu, X. New horizons for diagnostics and therapeutic applications of graphene and graphene oxide. Adv. Mater. 2013, 25, 168-186.

(3) Zhang, B.; Wang, Y.; Zhai, G. Biomedical applications of the graphene-based materials. Mater. Sci. Eng., C 2016, 61, 953-964.

(4) Cheng, C.; Li, S.; Kotov, N. A.; Haag, R. Functional graphene nanomaterials based architectures: Biointeractions, fabrications and emerging biological applications. Chem. Rev. 2017, 117, 1826-1914.

(5) Fattahi, P.; Yang, G.; Kim, G.; Abidian, M. R. A review of organic and inorganic biomaterials for neural interfaces. Adv. Mater. 2014, 26, $1846-1885$

(6) López-Dolado, E.; González-Mayorga, A.; Portolés, M. T.; Feito, M. J.; Ferrer, M. L.; del Monte, F.; Gutiérrez, M. C.; Serrano, M. C. Subacute tissue response to $3 \mathrm{D}$ graphene oxide scaffolds implanted in the injured rat spinal cord. Adv. Healthc. Mater. 2015, 4, 1861-1868.

(7) Kumar, S.; Chatterjee, K. Comprehensive review on the use of graphene-based substrates for regenerative medicine and biomedical devices. ACS Appl. Mater. Interfaces 2016, 8, 26431-26457.

(8) Orive, G.; Anitua, E.; Pedraz, J. L.; Emerich, D. F. Biomaterials for promoting brain protection, repair and regeneration. Nat. Rev. Neurosci. 2009, 10, 682-692.

(9) Bussy, C.; Ali-Boucetta, H.; Kostarelos, K. Safety considerations for graphene: lessons learnt from carbon nanotubes. Acc. Chem. Res. 2013, 46, 692-701.

(10) Pinto, A. M.; Gonçalves, I. C.; Magalhães, F. D. Graphene-based materials biocompatibility: a review. Colloids Surf., B 2013, 111, 188202.

(11) Solanki, A.; Chueng, S. T. D.; Yin, P. T.; Kappera, R.; Chhowalla, M.; Lee, K. B. Axonal alignment and enhanced neuronal differentiation of neural stem cells on graphene-nanoparticle hybrid structures. Adv. Mater. 2013, 25, 5477-5482.

(12) Akhavan, O.; Ghaderi, E. Differentiation of human neural stem cells into neural networks on graphene nanogrids. J. Mater. Chem. B 2013, 1, 6291-6301.

(13) Defterali, Ç.; Verdejo, R.; Peponi, L.; Martín, E. D.; MartínezMurillo, R.; López-Manchado, M. A.; Vicario-Abejón, C. Thermally reduced graphene is a permissive material for neurons and astrocytes and de novo neurogenesis in the adult olfactory bulb in vivo. Biomaterials 2016, 82, 84-93.

(14) López-Dolado, E.; González-Mayorga, A.; Gutiérrez, M. C.; Serrano, M. C. Immunomodulatory and angiogenic responses induced by graphene oxide scaffolds in chronic spinal hemisected rats. Biomaterials 2016, 99, 72-81.

(15) Cheng, H.; Hu, C.; Zhao, Y.; Qu, L. Graphene fiber: a new material platform for unique applications. NPG Asia Mater. 2014, 6, No. e113.

(16) Meng, F.; Lu, W.; Li, Q.; Byun, J. H.; Oh, Y.; Chou, T. W. Graphene-Based Fibers: A Review. Adv. Mater. 2015, 27, 5113-5131.

(17) Guo, W.; Zhang, X.; Yu, X.; Wang, S.; Qiu, J.; Tang, W.; Li, L.; Liu, H.; Wang, Z. L. Self-powered electrical stimulation for enhancing neural differentiation of mesenchymal stem cells on graphenepoly(3,4-ethylenedioxythiophene) hybrid microfibers. ACS Nano 2016, 10, 5086-5095.

(18) Guo, W.; Qiu, J.; Liu, J.; Liu, H. Graphene microfiber as a scaffold for regulation of neural stem cells differentiation. Sci. Rep. 2017, 7, No. 5678.

(19) Feng, Z. Q.; Wang, T.; Zhao, B.; Li, J.; Jin, L. Soft graphene nanofibers designed for the acceleration of nerve growth and development. Adv. Mater. 2015, 27, 6462-6468.

(20) Akhavan, O.; Ghaderi, E.; Shirazian, S. A.; Rahighi, R. Rolled graphene oxide foams as three-dimensional scaffolds for growth of neural fibers using electrical stimulation of stem cells. Carbon 2016, 97, $71-77$.
(21) Zhang, K.; Zheng, H.; Liang, S.; Gao, C. Aligned PLLA nanofibrous scaffolds coated with graphene oxide for promoting neural cell growth. Acta Biomater. 2016, 37, 131-142.

(22) Hua, C.; Shang, Y.; Li, X.; Hu, X.; Wang, Y.; Wang, X.; Zhang, Y.; Li, X.; Duan, H.; Cao, A. Helical graphene oxide fibers as a stretchable sensor and an electrocapillary sucker. Nanoscale 2016, 8, 10659-10668.

(23) Hyun, J. K.; Kim, H. W. Clinical and experimental advances in regeneration of spinal cord injury. J. Tissue Eng. 2010, 2010, No. 650857.

(24) Caron, I.; Rossi, F.; Papa, S.; Aloe, R.; Sculco, M.; Mauri, E.; Sacchetti, A.; Erba, E.; Panini, N.; Parazzi, V.; Barilani, M.; Forloni, G.; Perale, G.; Lazzari, L.; Veglianese, P. A new three dimensional biomimetic hydrogel to deliver factors secreted by human mesenchymal stem cells in spinal cord injury. Biomaterials 2016, 75, 135147.

(25) Li, G.; Che, M. T.; Zhang, K.; Qin, L. N.; Zhang, Y. T.; Chen, R. Q.; Rong, L. M.; Liu, S.; Ding, Y.; Shen, H. Y.; Long, S. M.; Wu, J. L.; Ling, E. A.; Zeng, Y. S. Graft of the NT-3 persistent delivery gelatin sponge scaffold promotes axon regeneration, attenuates inflammation, and induces cell migration in rat and canine with spinal cord injury. Biomaterials 2016, 83, 233-248.

(26) Yang, Z.; Zhang, A.; Duan, H.; Zhang, S.; Hao, P.; Yee, K.; Sun, Y. E.; Lia, X. NT3-chitosan elicits robust endogenous neurogenesis to enable functional recovery after spinal cord injury. Proc. Natl. Acad. Sci. U.S.A. 2015, 112, 13354-13359.

(27) Fabbro, A.; Bosi, S.; Ballerini, L.; Prato, M. Carbon nanotubes: Artificial nanomaterials to engineer single neurons and neuronal networks. ACS Chem. Neurosci. 2012, 3, 611-618.

(28) Serrano, M. C.; Patiño, J.; García-Rama, C.; Ferrer, M. L.; Fierro, J. L. G.; Tamayo, A.; Collazos-Castro, J. E.; del Monte, F.; Gutiérrez, M. C. 3D free-standing porous scaffolds made of graphene oxide as substrates for neural cell growth. J. Mater. Chem. B 2014, 2, 5698-5706.

(29) Dong, Z.; Jiang, C.; Cheng, H.; Zhao, Y.; Shi, G.; Jiang, L.; Qu, L. Facile fabrication of light, flexible and multifunctional graphene fibers. Adv. Mater. 2012, 24, 1856-1861.

(30) Bianco, A. Graphene: safe or toxic? The two faces of the medal. Angew. Chem., Int. Ed. Engl. 2013, 52, 4986-4997.

(31) Botas, C.; Álvarez, P.; Blanco, C.; Santamaría, R.; Granda, M.; Gutiérrez, M. D.; Rodríguez-Reinoso, F.; Menéndez, R. Critical temperatures in the synthesis of graphene-like materials by thermal exfoliation-reduction of graphite oxide. Carbon 2013, 52, 476-485.

(32) Xu, Y.; Sheng, K.; Li, C.; Shi, G. Self-assembled graphene hydrogel via a one-step hydrothermal process. ACS Nano 2010, 4, 4324-4330.

(33) Meng, Y.; Zhao, Y.; Hu, C.; Cheng, H.; Hu, Y.; Zhang, Z.; Shi, $\mathrm{G}$.; $\mathrm{Qu}, \mathrm{L}$. All-graphene core-sheath microfibers for all-solid-state, stretchable fibriform supercapacitors and wearable electronic textiles. Adv. Mater. 2013, 25, 2326-2331.

(34) Liu, H. W.; Huang, W. C.; Chiang, C. S.; Hu, S. H.; Liao, C. H.; Chen, Y. Y.; Chen, S. Y. Arrayed rGOSH/PMASH microcapsule platform integrating surface topography, chemical cues, and electrical stimulation for three-dimensional neuron-like cell growth and neurite sprouting. Adv. Funct. Mater. 2014, 24, 3715-3724.

(35) Brushart, T. M.; Hoffman, P. N.; Royall, R. M.; Murinson, B. B.; Witzel, C.; Gordon, T. Electrical stimulation promotes motoneuron regeneration without increasing its speed or conditioning the neuron. J. Neurosci. 2002, 22, 6631-6638.

(36) Brusés, J. L. N-cadherin signaling in synapse formation and neuronal physiology. Mol. Neurobiol. 2006, 33, 237-252.

(37) Shah, S.; Yin, P. T.; Uehara, T. M.; Chueng, S. T. D.; Yang, L.; Lee, K. B. Guiding stem cell differentiation into oligodendrocytes using graphene-nanofiber hybrid scaffolds. Adv. Mater. 2014, 26, $3673-3680$

(38) Tu, Q.; Pang, L.; Chen, Y.; Zhang, Y.; Zhang, R.; Lu, B.; Wang, $\mathrm{J}$. Effects of surface charges of graphene oxide on neuronal outgrowth and branching. Analyst 2014, 139, 105-115. 
(39) Schuster, T.; Mühlstein, A.; Yaghootfam, C.; Maksimenko, O.; Shipulo, E.; Gelperina, S.; Kreuter, J.; Gieselmann, V.; Matzner, U. Potential of surfactant-coated nanoparticles to improve brain delivery of arylsulfatase A. J. Controlled Release 2017, 253, 1-10.

(40) Guo, R.; Zhang, S.; Xiao, M.; Qian, F.; He, Z.; Li, D.; Zhang, X.; Li, H.; Yang, X.; Wang, M.; Chai, R.; Tang, M. Accelerating bioelectric functional development of neural stem cells by graphene coupling: Implications for neural interfacing with conductive materials. Biomaterials 2016, 106, 193-204.

(41) Arellano, J. I.; Benavides-Piccione, R.; DeFelipe, J.; Yuste, R. Ultrastructure of dendritic spines: correlation between synaptic and spine morphologies. Front. Neurosci. 2007, 1, 131-143.

(42) Kwon, S. E.; Chapman, E. R. Synaptophysin regulates the kinetics of synaptic vesicle endocytosis in central neurons. Neuron 2011, 70, 847-854.

(43) Min, K. J.; Kim, T. H.; Choi, J. W. Magnetic force-driven graphene patterns to direct synaptogenesis of human neuronal cells. Materials 2017, 10, 1151.

(44) Li, Y.; Feng, L.; Shi, X.; Wang, X.; Yang, Y.; Yang, K.; Liu, T.; Yang, G.; Liu, Z. Surface coating-dependent cytotoxicity and degradation of graphene derivatives: towards the design of nontoxic, degradable nano-graphene. Small 2014, 10, 1544-1554.

(45) Bussy, C.; Hadad, C.; Prato, M.; Bianco, A.; Kostarelos, K. Intracellular degradation of chemically functionalized carbon nanotubes using a long-term primary microglial culture model. Nanoscale 2016, 8, 590-601.

(46) Fawcett, J. W.; Schwab, M. E.; Montani, L.; Brazda, N.; Müller, H. W. Defeating inhibition of regeneration by scar and myelin components. Handb. Clin. Neurol. 2012, 109, 503-522.

(47) Seong, E.; Yuan, L.; Arikkath, J. Cadherins and catenins in dendrite and synapse morphogenesis. Cell Adhes. Migr. 2015, 9, 202213.

(48) Ren, T.; Yu, S.; Mao, Z.; Gao, C. A complementary density gradient of zwitterionic polymer brushes and NCAM peptides for selectively controlling directional migration of Schwann cells. Biomaterials 2015, 56, 58-67.

(49) Hadler, C.; Alious, P.; Brandes, G.; Warnecke, A.; Bohlmann, J.; Dempwolf, W.; Menzel, H.; Lenarz, T.; Reuter, G.; Wissel, K. Polymer coatings of cochlear implant electrode surface - An option for improving electrode-nerve-interface by blocking fibroblast overgrowth. PLoS One 2016, 11, No. e0157710.

(50) Alves-Sampaio, A.; García-Rama, C.; Collazos-Castro, J. E. Biofunctionalized PEDOT-coated microfibers for the treatment of spinal cord injury. Biomaterials 2016, 89, 98-113.

(51) Collazos-Castro, J. E.; Hernández-Labrado, G. R.; Polo, J. L.; García-Rama, C. N-Cadherin- and L1-functionalised conducting polymers for synergistic stimulation and guidance of neural cell growth. Biomaterials 2013, 34, 3603-3617.

(52) Carballo-Vila, M.; Moreno-Burriel, B.; Chinarro, E.; Jurado, J. R.; Casañ-Pastor, N.; Collazos-Castro, J. E. Titanium oxide as substrate for neural cell growth. J. Biomed. Mater. Res., Part A 2009, 90, 94-105. 